\title{
Análise das variáveis térmicas e correlação com os espaçamentos dendríticos e microssegregação na solidifıcação unidirecional da liga binária $\mathrm{Al}-4 \% \mathrm{Cu}$
}

Analysis of thermal variables and correlation with dendritic spacing and
microssegregation in the unidirectional solidification of Al-4\% Cu binary alloy

1 Nathália de Paula Sousa nathalia_sousa@id.uff.br

2 Wysllan Jefferson Lima Garção

1 Wemberson Bitencourt Chrisóstimo

1 Roberto Carlos Sales

1 Alexandre Furtado Ferreira

1 Universidade Federal Fluminense

2 Instituto Federal de Educação, Ciência e Tecnologia do Rio de Janeiro

\section{Resumo}

O alumínio (Al) e suas ligas constituem um dos materiais metálicos mais versáteis, econômicos e atrativos para uma vasta série de aplicações. Sua aplicação como metal estrutural só é menor que a dos aços. $\mathrm{O}$ cobre $(\mathrm{Cu})$ é adicionado às ligas de alumínio para aumentar sua resistência mecânica, dureza, resistência à fadiga e usinabilidade. As primeiras e mais utilizadas ligas de alumínio são aquelas contendo entre 4 a $10 \% \mathrm{Cu}$, em peso. Diversas aplicações industriais, tais como nos setores automotivo e aeronáutico, que necessitam de resistência e tenacidade, utilizam ligas do sistema Al-Cu. Como as condições do processo de solidificação influenciam na microestrutura, é proposto um estudo da relação entre as variáveis térmicas na macro/microestrutura, nos espaçamentos dendríticos e na microssegregação de uma liga binária hipoeutética Al-Cu. A metodologia consiste em realizar um experimento de solidificação unidirecional vertical descendente, mantendo o superaquecimento em $15 \%$ acima da temperatura liquidus, realizando monitoramento da solidificação por meio das curvas de resfriamento. Com base nos resultados experimentais obtidos pelo presente trabalho, podem se extrair que as equações empíricas obtidas por meio da função potência apresentaram uma boa correlação com os resultados experimentais e pôde-se obter uma equação experimental para definição do perfil de concentração de soluto ao longo da fração sólida nas regiões de espaçamento dendrítico terciário.

Palavras-chave:

Espaçamentos dendríticos. Microssegregação. Solidificação unidirecional. Variáveis térmicas.

\begin{abstract}
Aluminum (Al) and its alloys are one of the most versatile, economical and attractive metal materials for a wide range of applications. Its application as structural metal is only smaller than that of steels. Cooper $(\mathrm{Cu})$ is added to aluminum alloys to increase its mechanical strength, hardness, fatigue strength and machinability. The first and most commonly used aluminum alloys are those containing from 4 to $10 \% \mathrm{Cu}$ by weight. Several industrial applications, such as in the automotive and aeronautical sectors, which require strength and toughness, use Al-Cu alloys. As the conditions of the solidification process influence the microstructure, it is proposed a study of the relationship between the thermal variables in the macro/microstructure, in the dendritic spacings and in the microssegregation of an Al-Cu hypoeutectic binary alloy. The methodology consists in carrying out a downward vertical unidirectional solidification experiment, keeping the superheating at $15 \%$ above the liquidus temperature, monitoring the solidification by means of the cooling curves. Based on the experimental results obtained by the present work, it can be concluded that the empirical equations obtained by means of the power function showed a good correlation with the experimental results and an experimental equation was obtained to define the profile of solute concentration along the fraction in the tertiary dendritic spacing regions.
\end{abstract}

\section{Keywords:}

Dendritic spacing. Microssegregation. Unidirectional solidification. Thermal variables.

\section{Como você deve citar?}

SOUSA, Nathália de Paula et al. Análise das variáveis térmicas e correlação com os espaçamentos dendríticos e microssegregação na solidificação unidirecional da liga binária Al-4\%Cu. Cadernos UniFOA, Volta Redonda, n. 40, p. 5-17, agosto 2019. 
Análise das variáveis térmicas e correlação com os espaçamentos dendríticos

e microssegregação na solidificação unidirecional da liga binária $\mathrm{Al}-4 \% \mathrm{Cu}$.

\section{INTRODUÇÃO}

Grande parte dos processos produtivos de um material metálico inicia-se na solidificação, sendo assim, pode-se afirmar que a solidificação é um dos processos mais presentes nas indústrias de transformação desses materiais.

Ligas leves à base de Alumínio (Al) proporcionam significativos benefícios na substituição de materiais mais tradicionais da indústria aeroespacial, automotiva, naval, dentre outras, já que as características intrínsecas desse metal (e de suas ligas) conferem, geralmente, melhor desempenho com economia no consumo de combustíveis, redução na emissão de poluentes e maior resistência à degradação por corrosão. Com isso, estudos desenvolvidos em processos de solidificação de ligas de Al-Cu permitem obter conhecimentos que serão de grande interesse da comunidade científica e industrial.

Em estudos de Garcia (2007), algumas variáveis térmicas são significativas para o controle da microestrutura de solidificação e todas são sintetizadas para ligas binárias no critério do super-resfriamento, como a velocidades de deslocamento da isoterma liquidus $(\mathrm{VL})$, os gradientes térmicos à frente da interface sólido/líquido (GL) e as taxas de resfriamento ( ). De acordo com Spinelli et al. (2007), em condições transitórias de extração de calor, essas variáveis térmicas são interdependentes, ou seja, não podem ser controladas e variam continuamente ao longo do processo.

Do ponto de vista experimental, a técnica de solidificação unidirecional tem sido bastante utilizada em estudos de caracterização de aspectos da macroestrutura, microestrutura e de análise da segregação de soluto (PERES et al., 2004).

Burden et al. (1976) e Hui et al. (2002) mostraram que, poucos estudos têm analisado o efeito da solidificação unidirecional no líquido interdendrítico, bem como a influência da direção de crescimento em relação à gravidade nos espaçamentos dendríticos.

O objetivo deste trabalho foi estudar a relação entre as variáveis térmicas na macro/microestrutura, nos espaçamentos dendríticos e na microssegregação de uma liga binária hipoeutética Al-Cu. Foi utilizado um dispositivo de solidificação unidirecional vertical descendente constituído por uma lingoteira de aço inox. Na parte superior, foi posicionada uma câmara de refrigeração à água do mesmo material do molde. Após a obtenção dos lingotes e registro do perfil térmico, foram determinadas as variáveis de solidificação e, em seguida, correlacionadas com os espaçamentos dendríticos terciários. Para análise de microssegregação, as composições químicas de regiões interdendrítica foram obtidas com o auxílio de um microscópio eletrônico de varredura (MEV) acoplado a um sistema de análise por energia dispersiva (EDS).

\section{MATERIAIS E MÉTODOS} trabalho.

O fluxograma apresentado na Figura 1 descreve as etapas experimentais realizadas no presente 
Figura 1: Fluxograma dos métodos realizados.

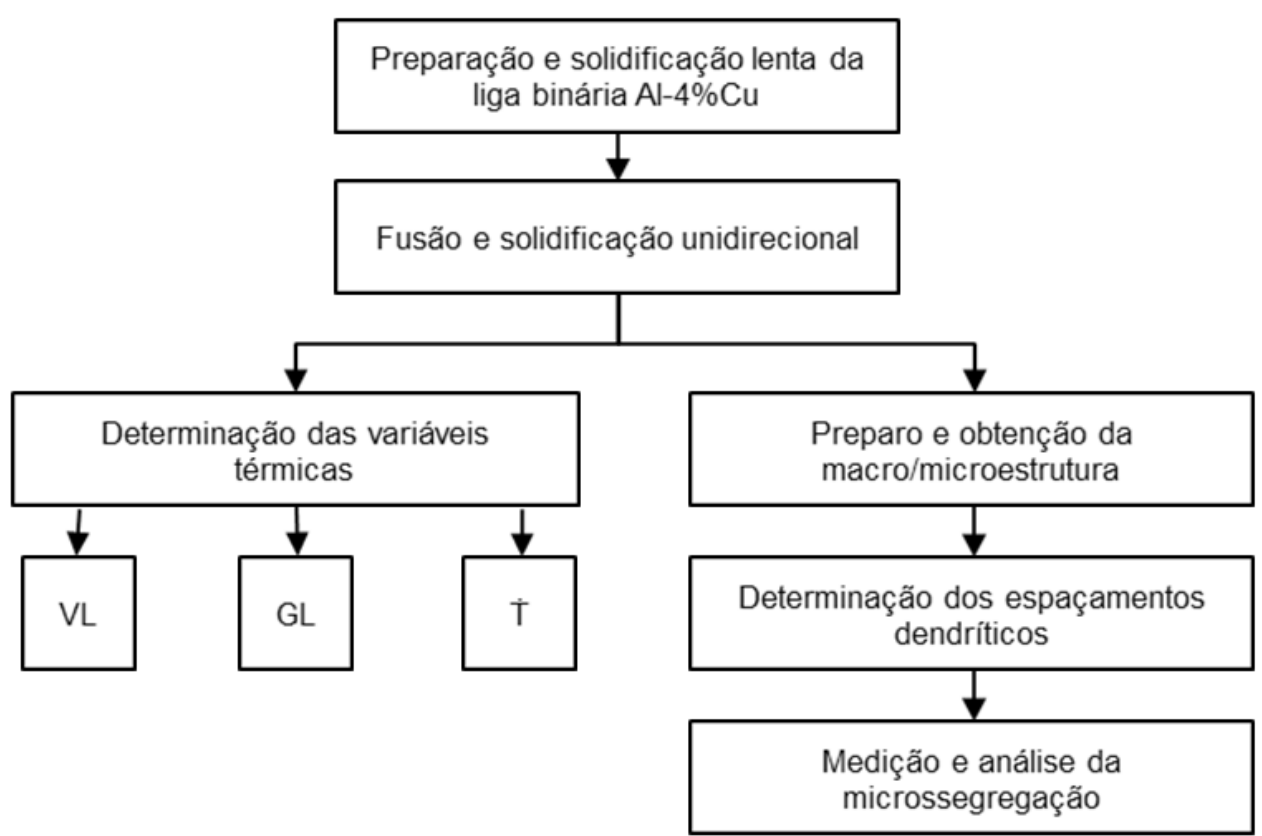

Fonte: autores, 2019

$\mathrm{Na}$ etapa de fusão da liga $\mathrm{Al}-4 \% \mathrm{Cu}$, foi necessário inserir o cadinho contendo o Al dentro do forno tipo Mufla e fundir a uma temperatura acima da temperatura liquidus, a fim de assegurar que o material permaneça no estado líquido durante a operação.

O cadinho foi retirado do forno após 60 minutos. Com auxílio de uma garra metálica, acrescentou-se o Cu de forma gradual e realizou-se a homogeneização do material. Logo após, o material retornou para o forno por mais 40 minutos.

O aparato de solidificação foi projetado de tal modo que a extração de calor seja realizada somente pela parte superior refrigerada à água, promovendo uma solidificação direcional vertical descendente, conforme Figura 2. 
Análise das variáveis térmicas e correlação com os espaçamentos dendríticos

e microssegregação na solidificação unidirecional da liga binária $\mathrm{Al}-4 \% \mathrm{Cu}$.

Figura 2: Forno de solidificação unidirecional vertical com refrigeração à água.

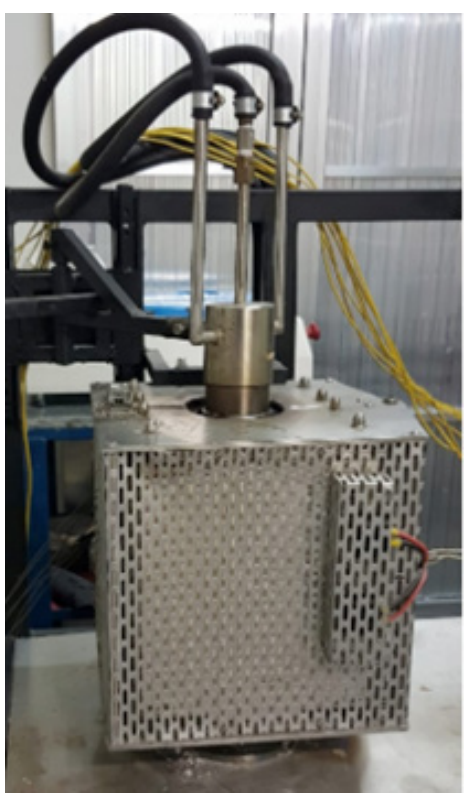

Fonte: autores, 2019.

As temperaturas no metal fundido foram monitoradas durante a solidificação por meio de um conjunto de 7 termopares tipo $\mathrm{K}$ localizados no metal líquido nas posições $(5,10,15,30,40,55$ e 80 $\mathrm{mm}$ ) em relação à interface superior metal/molde.

Após a preparação dos termopares, o cadinho foi inserido com o material no forno elétrico e mantido até $900^{\circ} \mathrm{C}$. O líquido foi vazado na lingoteira, que se encontrava no forno de solidificação pré-aquecido em $900^{\circ} \mathrm{C}$.

Ao atingir uma temperatura de, aproximadamente, $15 \%$ acima da TL (Temperatura liquidus), ou seja, $750^{\circ} \mathrm{C}$, a bomba hidráulica foi ligada, direcionando a água na parte superior da lingoteira e o forno de solidificação foi simultaneamente desligado. Dessa forma, a solidificação foi processada no sentido descendente.

Após o metal líquido ter sido vazado no molde, o sistema de aquisição de dados foi ligado e as temperaturas foram monitoradas e registradas durante a solidificação em condições transientes à extração de calor. As variáveis térmicas $(\mathrm{VL}$, e GL) foram determinadas experimentalmente após a obtenção das curvas de resfriamento lento.

Após a preparação das amostras e obtenção das micrografias, foi realizada a medição dos espaçamentos dendríticos terciários por meio de um software interconectado com um microscópio óptico e da microssegregação com o auxílio de um microscópio eletrônico de varredura e software para análise química por meio de espectroscopia de energia dispersiva.

\section{RESULTADOS E DISCUSSÕES}

Este capítulo apresenta os resultados do experimento realizado no processo de solidificação da liga binária de $\mathrm{Al}-4 \% \mathrm{Cu}$. 


\subsection{Mapeamento do perfil térmico do lingote e macroestrutura}

O mapeamento do perfil térmico do lingote obtido experimentalmente, para a liga binária de Al$4 \% \mathrm{Cu}$, após o processo de solidificação sob condições transientes à extração de calor e macroestrutura obtida estão apresentados na Figura. 3.

Figura 3: a) Perfil térmico e b) macroestrutura da liga binária Al-4\%Cu

a)

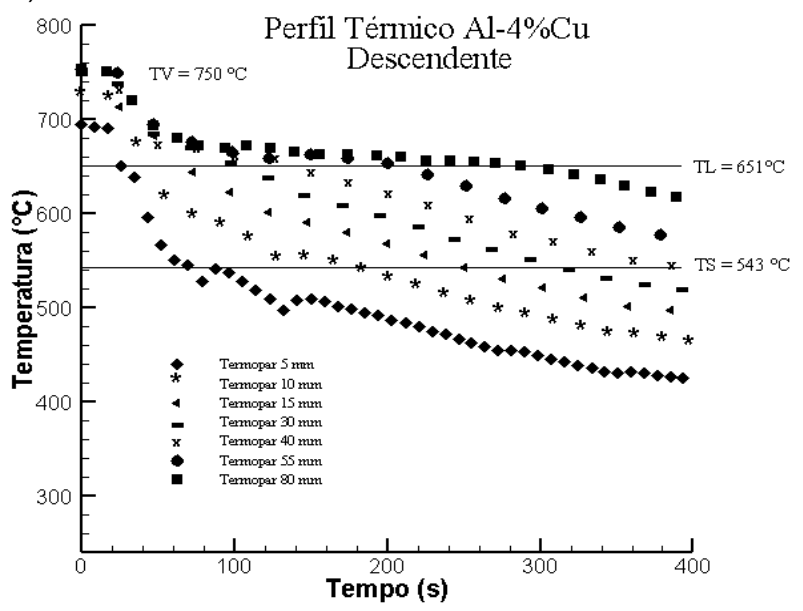

b)

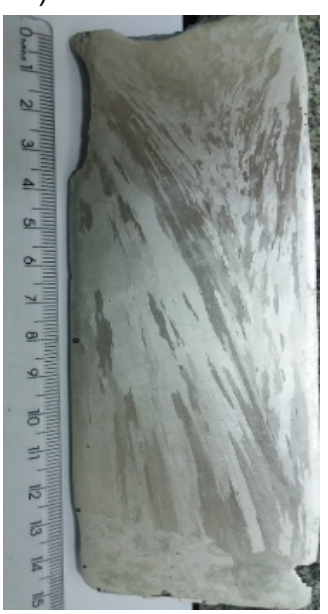

Fonte: autores, 2019

De acordo com o mapeamento realizado, a temperatura de vazamento (TV) foi de, aproximadamente, $750^{\circ} \mathrm{C}$, conforme Figura 3a. Tal temperatura permite que o metal líquido se acomode no molde antes do início da solidificação, pois ela corresponde a cerca de $15 \%$ acima da temperatura liquidus (TL). As inclinações das curvas de resfriamento podem ser justificadas pela queda abrupta da temperatura ao acionar o sistema de resfriamento do forno de solidificação. A maior inclinação das curvas foi obtida nos termopares mais próximos da base refrigerada.

Pode-se perceber que, conforme a Figura 3b, notaram-se grãos colunares com uma direcionalidade no sentido vertical, atestando a eficácia da extração de calor no processo de solidificação, conforme em outros estudos (MEZA, 2012; RODRIGUES et al., 2014; BAPTISTA et al., 2018; FERREIRA et al., 2017; BOEIRA, 2006). Observou-se também uma leve inclinação que pode ser causada por perturbações mecânicas externas durante a solidificação, de acordo com Garcia (2007).

\subsection{Caracterização da microestrutura}

As microestruturas observadas ao longo da seção transversal da liga binária Al-4\%Cu solidificada unidirecionalmente apresentaram morfologia dendrítica em todas as posições $(5,10,15,30,40,55$ e 80) $\mathrm{mm}$ a partir da interface metal/molde, conforme apresentado na Figura $4 \mathrm{a}$ até $4 \mathrm{~g}$. 
Figura 4: Micrografias observadas na seção transversal da liga $\mathrm{Al}-4 \% \mathrm{Cu}$. P é a posição de referência a partir da interface entre metal e câmara de refrigeração.

(a)

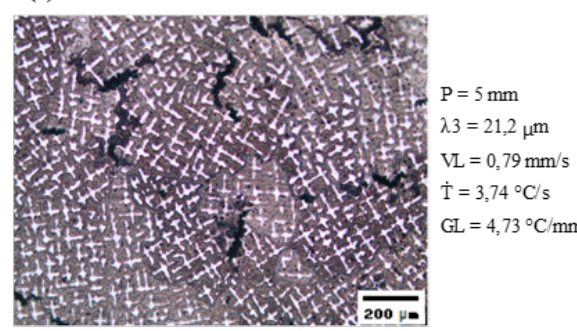

(c)

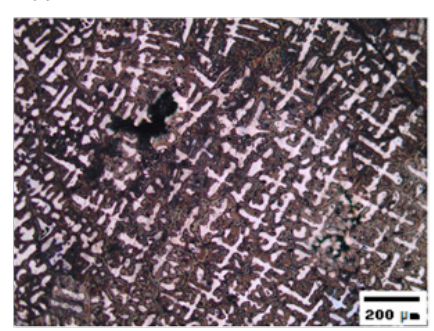

(e)

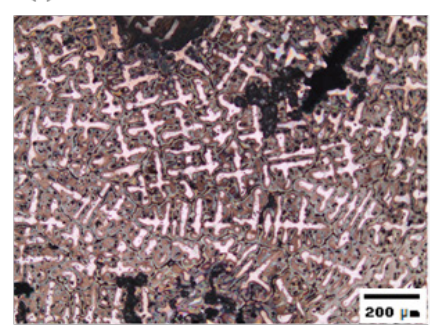

(g)

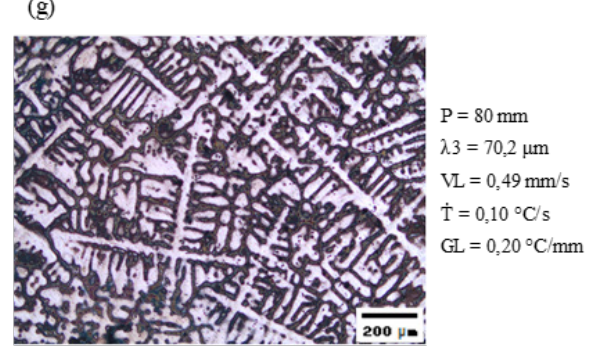

(b)

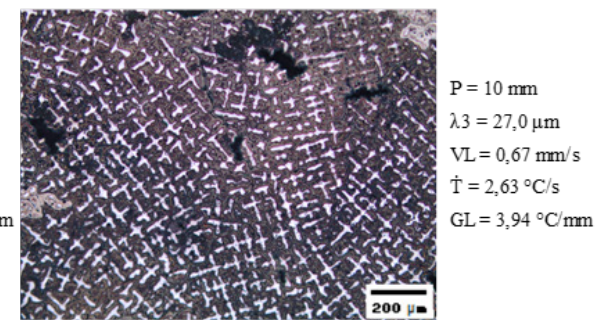

(d)

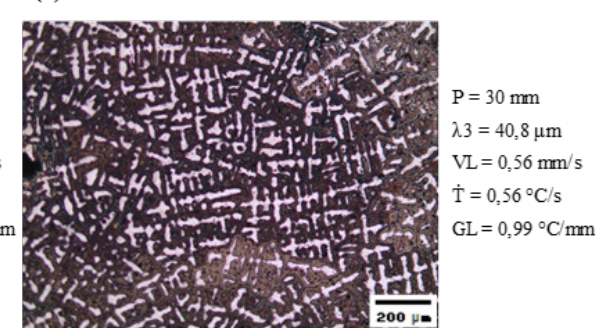

(f)

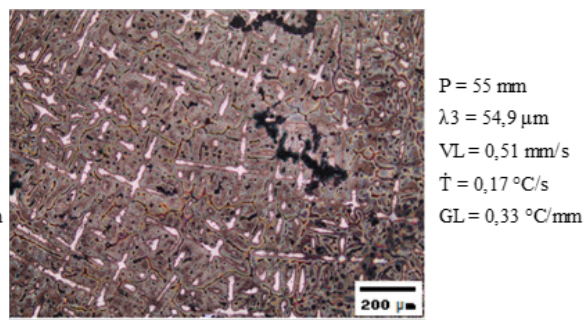

Fonte: autores, 2019.

As regiões escuras nas micrografias representam as regiões localizadas entre os emaranhados de braços dendríticos, última região solidificada contendo os solutos segregados durante a solidificação.

Nota-se que todas as micrografias apresentaram porosidades interdendríticas como consequências da rápida solidificação obtida pelo resfriamento forçado realizado nos experimentos.

\subsection{Caracterização da microestrutura}

O tempo de passagem da isoterma liquidus foi determinado por meio do perfil térmico do lingote do $\mathrm{Al}-4 \% \mathrm{Cu}$, conforme a Figura 3a. 0 gráfico apresentado na Figura 5 representa o tempo (t) em que cada termopar, com sua respectiva posição $(\mathrm{P})$ a partir da interface metal/molde, atingir a TL.

Uma técnica de ajuste por curva a esses pontos experimentais gerou uma expressão algébrica de posição em função do tempo. 
Figura 5: Curva posição versus tempo.

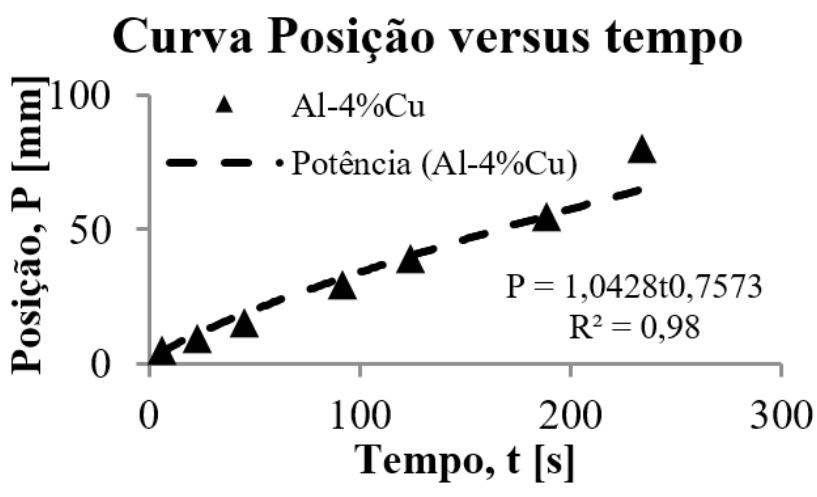

Fonte: autores, 2019

\subsection{Análise das variáveis térmicas}

A velocidade de deslocamento da isoterma liquidus (VL) foi obtida a partir da derivada da função $P=f(t)$. Dessa forma, a dP/dt, possibilitou a obtenção dos respectivos valores experimentais para as velocidades de deslocamento da isoterma liquidus a partir da interface metal/molde em função da posição, o que corresponde à passagem da frente líquida por cada termopar, conforme Figura 6 .

Figura 6: Velocidade de deslocamento da isoterma liquidus em função da posição.

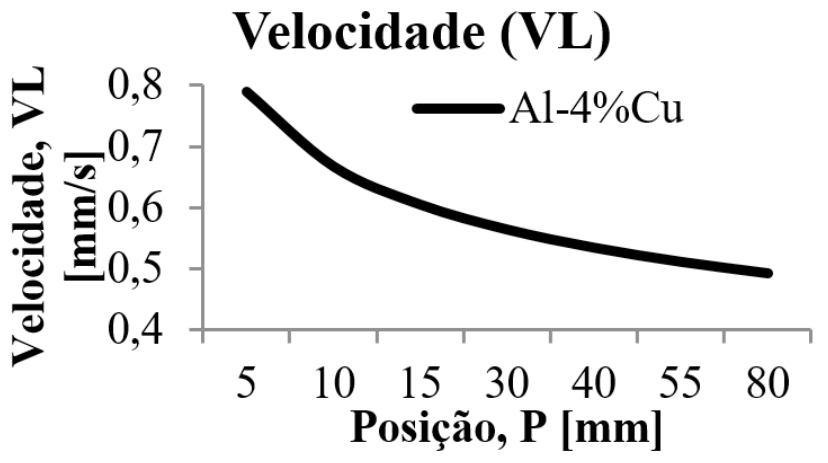

Fonte: autores, 2019.

A taxa de resfriamento para cada posição dos termopares foi obtida experimentalmente a partir das interseções da reta da temperatura liquidus com os perfis térmicos equivalentes a cada posição dos termopares, por meio do resultado da leitura direta do quociente das temperaturas imediatamente antes e depois da temperatura liquidus e dos tempos correspondentes, ou seja, dT/dt.

Assim, com base nos pontos experimentais, foram geradas funções potência da taxa de resfriamento em função da posição, conforme Figura 7. 
Figura 7: Taxa de resfriamento em função da posição.

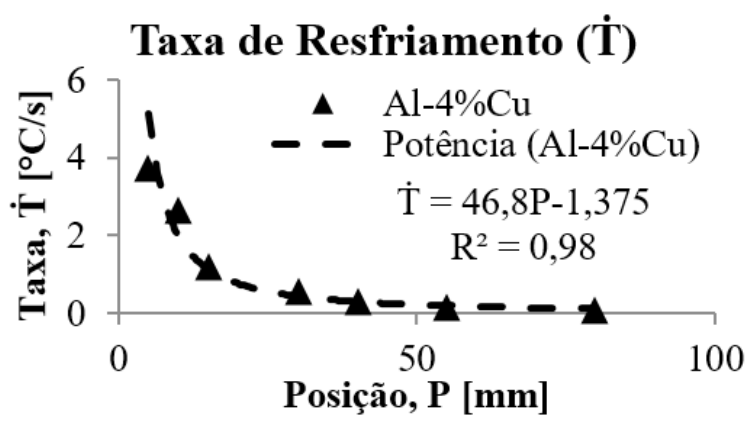

Fonte: autores, 2019.

0 gradiente térmico da isoterma liquidus foi determinado por meio do perfil térmico do lingote de $\mathrm{Al}-4 \% \mathrm{Cu}$, apresentado na Figura 8 , em função da posição, ou seja, dT/dP, com base no quociente das velocidades de deslocamento da isoterma liquidus e as taxas de resfriamento correspondentes para cada posição dos termopares.

Figura 8: Gradiente térmico em função da posição.

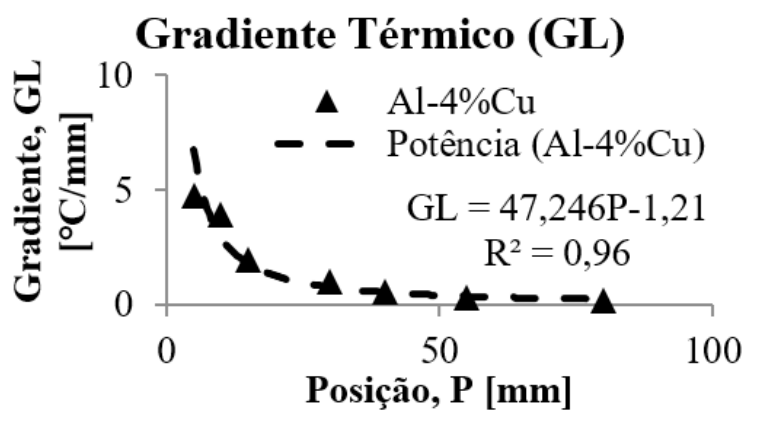

Fonte: autores, 2019.

A velocidade de deslocamento da isoterma liquidus diminuiu abruptamente, quando iniciado o processo de solidificação, devido à proximidade com a base refrigerada. À medida que a interface liquidus/solidus avança, ocorre uma diminuição gradual da velocidade ao longo do tempo, devido ao aumento da resistência térmica da camada solidificada.

Os valores da taxa de resfriamento são menores nas posições mais afastadas da base do lingote. 0 tempo de deslocamento da isoterma liquidus foi maior em tais posições, podendo justificar o comportamento decrescente da taxa de resfriamento em relação à posição.

O gradiente térmico foi maior nas regiões mais próximas da base. 0 sistema de refrigeração à água favorece uma maior taxa de solidificação no início do processo, diminuindo-a gradativamente, por causa do aumento da resistência térmica da camada solidificada. 


\subsection{Correlação das variáveis térmicas com os espaçamentos dendríticos terciários}

O método a ser utilizado para calcular o espaçamento dendrítico terciário $\left(\lambda_{3}\right)$ é a média das distâncias entre os braços adjacentes (ramificações terciárias) sobre a seção longitudinal (paralela ao eixo de calor ou a direção de crescimento) de uma ramificação dendrítica primária (MCCARTNEY et al., 1981).

Foi obtida uma amostragem de 10 medições para cada uma das sete posições para a liga Al$4 \% \mathrm{Cu}$. As Figuras 9, 10 e 11 apresentam os valores médios dos espaçamentos dendríticos em função da VL, †ं e GL, respectivamente.

Figura 9: Espaçamento dendrítico terciário em função da velocidade de deslocamento da isoterma liquidus.

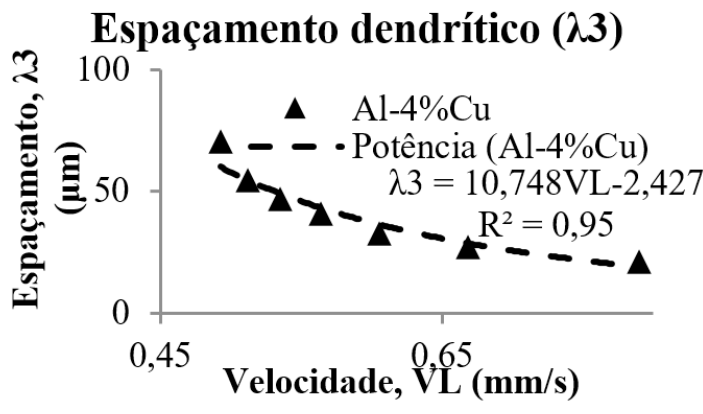

Fonte: autores, 2019

Figura 10: Espaçamento dendrítico terciário em função da taxa de resfriamento para a liga binária $\mathrm{Al}-4 \% \mathrm{Cu}$.

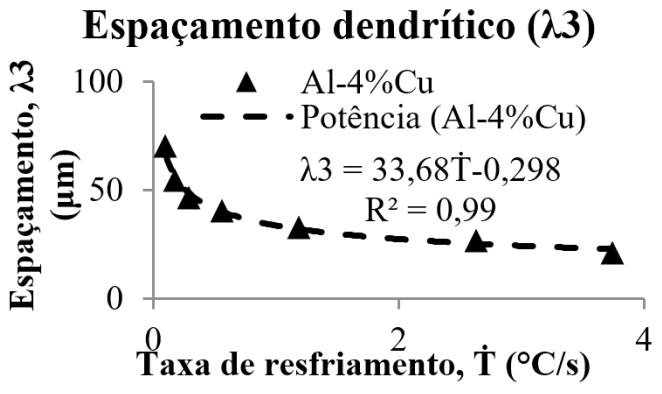

Fonte: autores, 2019. 
Figura 11: Espaçamento dendrítico terciário em função do gradiente térmico para a liga binária Al-4\%Cu.

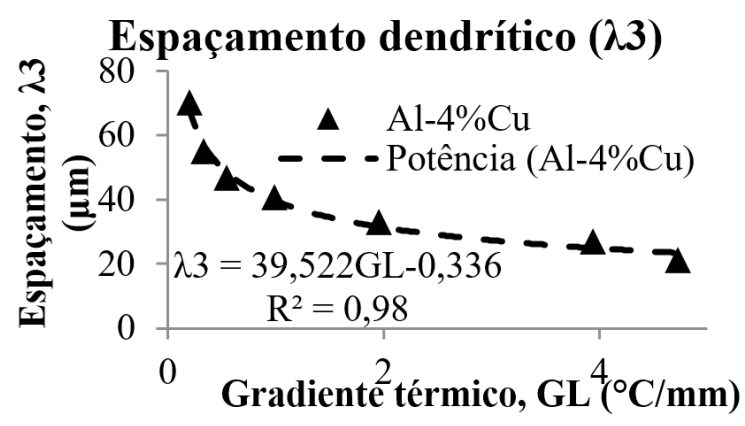

Fonte: autores, 2019.

O espaçamento dendrítico terciário ao longo do lingote possui uma relação direta com as variáveis térmicas estudadas no presente trabalho e os resultados experimentais comparados com as equações potência obtidas apresentaram uma boa correlação.

De acordo com as Figuras 9, 10 e 11, observa-se que, para maiores velocidades de deslocamento da isoterma liquidus, taxa de resfriamento e gradiente térmico, menores são os valores dos espaçamentos dendríticos terciários. Tal fato pode ser explicado em função do fluido de refrigeração impor valores de VL, †ं e GL elevados próximos à interface metal/molde, os quais diminuem gradativamente durante a solidificação em função do aumento da resistência térmica promovida pela progressiva formação do metal sólido.

Tais valores podem ser representados por equações na forma de potência em função dos parâmetros térmicos, por $\lambda_{3}=10,748 \mathrm{VL}^{-2,427}, \lambda_{3}=33,68 \mathrm{~T}^{-0,298}$ e $\lambda_{3}=39,522 \mathrm{GL}^{-0,336}$.

De acordo com trabalhos propostos por outros autores (ROSA, 2004; MEZA, 2012), os resultados apresentaram uma boa concordância com o esperado.

\subsection{Análise da microssegregação}

Está sendo proposto, neste trabalho, uma lei experimental que permite descrever o comportamento das concentrações médias de soluto para diferentes velocidades de deslocamento da isoterma liquidus (MEZA et al., 2013).

A equação experimental se baseia na curva de melhor ajuste ao perfil de microssegregação experimental, conforme demonstrada na equação a seguir.

$$
C_{S}=C_{0} \cdot k_{e f}+a \cdot \exp \left(b \cdot f_{s}\right)
$$

onde, a e b são constantes experimentais, Cs é a concentração de soluto no sólido, C0 é a concentração de soluto em equilíbrio e kef é o coeficiente efetivo distribuição de soluto. 
O cálculo do coeficiente efetivo de distribuição de soluto pode ser obtido pela equação abaixo (BURTON et al., 1953).

$$
k_{e f}=\frac{k}{k+(1-k) \exp \left(\frac{-v \delta}{D}\right)}
$$

A Tabela 1 apresenta as propriedades físicas da liga binária Al-Cu utilizadas no presente trabalho.

Tabela 1: Propriedades físicas.

\begin{tabular}{llll}
\hline Propriedade física & Símbolo & Valor & Unidade \\
\hline Difusividade do soluto na fase líquida & $\mathrm{D}$ & $3,6 \times 10^{-9}$ & $\mathrm{~m}^{2} \mathrm{~s}^{-1}$ \\
Coeficiente de redistribuição de soluto de equilíbrio & $\mathrm{k}$ & 0,1 & - \\
camada limite de difusão & $\delta$ & 0,01 & $\mathrm{~mm}$ \\
\hline
\end{tabular}

Fonte: GARCIA, 2007; FERREIRA et al., 2017

Na Figura 12, é apresentado o perfil de concentração de soluto no sólido (Cs) em função da fração sólida (fs) pela equação experimental, considerando-se as posições de 5, 40 e $80 \mathrm{~mm}$.

Figura 12: Perfil de concentração de soluto em função da fração sólida.

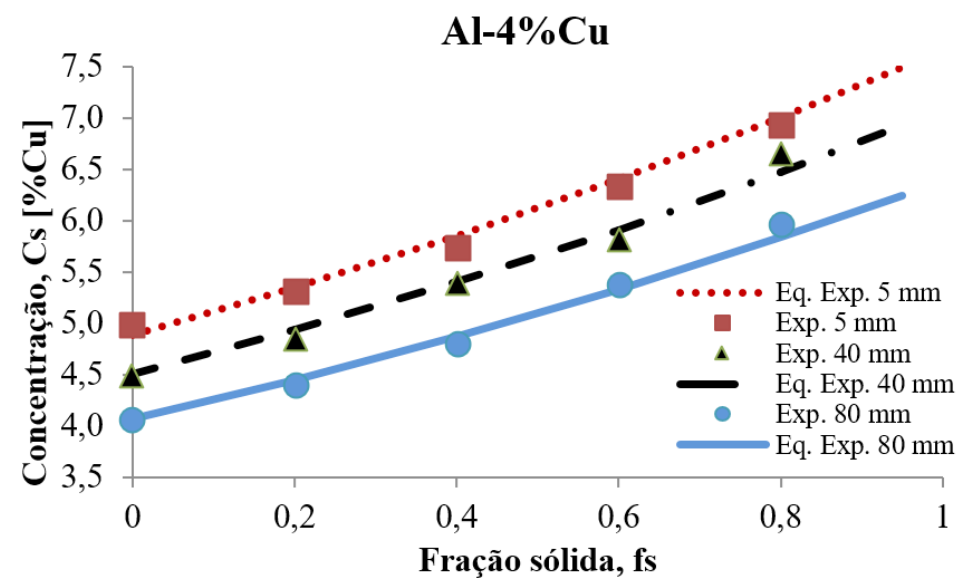

Fonte: autores, 2019.

Pode-se notar que, no formato proposto, a equação experimental representa bem a evolução da microssegregação em toda a faixa de velocidades analisada para a liga binária $\mathrm{Al}-4 \% \mathrm{Cu}$, em comparação com os resultados experimentais obtidos no presente trabalho. Para a constante "a" foram encontrados os valores de 4,862, 4,496 e 4,056 para as posições de $5 \mathrm{~mm}, 40 \mathrm{~mm}$ e $80 \mathrm{~mm}$, respectivamente. Já para a constante "b", foi encontrado o valor de 0,452 para as três posições analisadas.

A Tabela 2 apresenta os valores dos parâmetros empregados na equação experimental. 
Análise das variáveis térmicas e correlação com os espaçamentos dendríticos

e microssegregação na solidificação unidirecional da liga binária $\mathrm{Al}-4 \% \mathrm{Cu}$.

Tabela 2: Resumo dos parâmetros da equação experimental.

\begin{tabular}{lllll}
\hline Posição $(\mathbf{m m})$ & VL $(\mathbf{m m} / \mathbf{s})$ & Kef & a & b \\
\hline 5 & 0,7897 & 0,499 & 4,862 & \\
40 & 0,5641 & 0,347 & 4,496 & 0,452 \\
80 & 0,4925 & 0,304 & 4,056 & \\
\hline
\end{tabular}

Fonte: autores, 2019.

\section{CONCLUSÃO}

Com base nos resultados experimentais obtidos pelo presente trabalho, podem ser extraídas as seguintes conclusões:

As equações empíricas obtidas por meio da função potência apresentaram uma boa correlação com os resultados experimentais para a liga binária de $\mathrm{Al}-4 \% \mathrm{Cu}$.

Quanto mais afastados da base refrigerada, menores são os valores de VL, e GL. Tal fato pode ser explicado pela elevação da resistência térmica à extração de calor ao longo do processo de solidificação, devido ao aumento da camada solidificada.

Os espaçamentos dendríticos se correlacionam de forma inversa às variáveis térmicas, isto é, quanto maior os valores dessas variáveis, menores são os espaçamentos entre as ramificações dendríticas.

Uma equação experimental foi desenvolvida, baseando-se nas curvas de melhor ajuste aos resultados de concentração de soluto obtidos por meio da medição com MEV/EDS nos espaçamentos dendríticos terciários. Essa equação experimental apresenta uma boa concordância com os resultados experimentais obtidos no trabalho.

\section{AGRADECIMENTOS}

Os autores agradecem aos professores, funcionários e alunos do Programa de Pós-graduação em Engenharia Metalúrgica da Universidade Federal Fluminense.

\section{REFERÊNCIAS}

BAPTISTA, L. A. S.; FERREIRA, A. F.; PARADELA, K. G.; SILVA, D. M.; CASTRO, J. A. Experimental investigation of ternary Al-Si-Cu alloy solidified with unsteady-state heat flow conditions. Materials Research-Iberoamerican Journal of Materials, v. 1, p. 1-1, 2018.

BOEIRA, Alexandre Pitol. Macrossegregação e formação de poros na solidificação de ligas de Al-Cu: modelagem numérica e desenvolvimento experimental. Tese (Doutorado em Engenharia Mecânica) Universidade Estadual De Campinas, São Paulo, 2006. 
BURDEN, M. H.; HUNT, J. D. Some observations on primary dendrite spacings. Metals Science, p. 156158, 1976.

BURTON, J. A.; PRIM, R. C.; SLICHTER, W. P. The distribution of solute in crystals grown from the melt part I theoretical. Journal of Chemical Physics, v. 21, p. 187, 1953.

FERREIRA, A. F.; PARADELA, K. G.; FELIPE JR, P.; ALCÂNTARA JR, Z.; GARCIA, A. Phase-field simulation of microsegregation and dendritic growth during solidification of hypoeutectic Al-Cu alloys. Materials Research, São Carlos, v. 1, p. 1-0, 2017.

GARCIA, A. Solidificação: fundamentos e aplicações. 2. ed. São Paulo: Universidade Estadual de Campinas, 2007.

HUI, J.; TIWARI, R.; WU, X.; TEWARI, S. N.; TRIVEDI, R. Primary dendrite distribution and disorder during directional solidification of $\mathrm{Pb}-\mathrm{Sb}$ alloys. Metallurgical and Materials Transactions A, v. 33A, p. 34993510, 2002.

MCCARTNEY, D. G.; HUNT, J. D. Measurements of cell and primary dendrite arm spacing in directionally solidified aluminium alloys, Acta Metallurgica, v. 29, p. 1851-1863, 1981.

MEZA, Elisângela dos Santos. Modelagem analítica e numérica da solidificação de ligas binárias: análise de fatores de influência. Tese (Doutorado em Engenharia Mecânica) - Universidade Estadual De Campinas, São Paulo, 2012.

MEZA E. S.; BERTELLI, F.; GOULART, P. R.; CHEUNG, N.; GARCIA, A. The effect of the growth rate on microsegregation: Experimental investigation in hypoeutetic Al-Fe and Al-Cu alloys directionally solidified. Journal of Alloys and Cpounds, v. 561, p. 193-200, 2013.

PERES, M. D.; SIQUEIRA, C. A.; GARCIA, A. Macrostructural and microstructural development in Al-Si alloys directionally solidified under unsteady-state conditions. Journal of Alloys and Compounds. v. 381, p. 168-181. 2004.

RODRIGUES, J. R. P.; MELO, M. L. N. M.; EID, M. A.; NEVES, T. E. S. B.; JUNIOR, A. S. A. Comparative study of solidification of Al-Cu alloy under flow of cylindrical radial heat and the unidirectional vertically. Journal ActaScientlarum, p. 623-628, 2014.

ROSA, Daniel Monteiro. Caracterização da Microestrutura Dendrítica na Solidificação Vertical Descendente de Ligas Al-Cu. 2004. Dissertação (Mestrado em Engenharia Mecânica) - Universidade Estadual De Campinas, São Paulo, 2004.

SPINELLI, J. E.; GARCIA, A. Influence of melt convection on the columnar to equiaxed transition and microstructure of downward unsteady-state directionally solidified $\mathrm{Sn}-\mathrm{Pb}$ allys. Journal of Alloys and Compounds, v. 384, p. 217-226, 2004. 